\title{
NATURAL AND SYNTHETIC DYE COMPOUNDS: APPLICATIONS IN GLIOBLASTOMAS THERAPY
}

\author{
Oana Alexandrư ${ }^{1,2}$, Ada Maria Georgescu ${ }^{3}$, Laurentiu Ene $^{3}$, Valerica Tudorica ${ }^{1}$, \\ Anica Dricu ${ }^{2}$ \\ ${ }^{1}$ Neurology Department, University of Medicine and Pharmacy of Craiova \\ ${ }^{2}$ Department of Functional Sciences, University of Medicine and Pharmacy of Craiova \\ ${ }^{3}$ Department of Functional Sciences, University of Medicine and Pharmacy of Craiova
}

\begin{abstract}
Glioblastomas are the most aggressive high-grade gliomas, characterized by diffuse infiltrative growth, high migration potential, angiogenesis, predisposition for necrosis that are decisive steps in resistance to therapy. In spite of current advances, the treatment of these tumors remains a challenge for oncologists. Because of the poor prognosis of these patients, development and testing of more effective therapeutic strategies is undertaken by several medical scientific communities. One of the new classes of drugs that are tested in vivo and in vitro is represented by the dye-compounds. This review focuses on efficacy of these drugs and their mechanisms of action in glioblastomas.
\end{abstract}

Keywords: dye compounds, glioblastoma, therapy

\section{INTRODUCTION}

The most studied primary brain tumors in adults are high-grade gliomas (HGG) which represent over $60 \%$ of all primary brain tumors. HGGs arise by malignant transformation of astrocytes. According to the 2007 WHO (World Health Organization) classification of central nervous system tumors, high-grade gliomas are: diffuse astrocytomas (WHO malignancy grade II), anaplastic astrocytoma $\mathrm{s}$ (WHO malignancy grade III), and glioblastomas (WHO malignancy grade IV). (1) Glioblastomas (GB) are the most aggressive HGG, representing the most common malignant tumor $(45.6 \%)$ and the majority of gliomas. They may arise de novo or by malignant progression from astrocytoma. During the process of malignant transformation occurs a subsequent alteration in tumor-associated pathways, such as: PI3K/Akt, Ras/Raf/MAPK, p53/ MDM2/p14ARF. (2) In spite of current advances, the GB treatment remains a challenge for oncolo- gists. In ESMO (European Society for Medical Oncology) and NCI (National Cancer Institute) guidelines for the treatment of $G B$, it is recommended surgery as initial approach for newly diagnosed patients, followed by radiotherapy associated with concomitant or adjuvant termozolomide therapy. (3) Because of the poor prognosis of these patients, development and testing of more effective therapeutic strategies (including some new chemotherapeutic agents) is undertaken by several medical scientific comunities. Among the tested substances are dye-compounds. Dyes form a major class of natural and synthetic compounds known from antiquity for their properties as colorants but also known for a variety of therapeutic properties including anti-inflammatory, antioxidant and antiseptic activity. (4) These drugs are either natural (e.g. curcumin, quercetin, saffron, etc), or synthetic products (e.g. helianthin). In recent years, some dye compounds have shown promise both as potential antitumor agents

Author for correspondence:

Professor Anica Dricu, 2 Petru Rareş St, Craiova

E-mail: anica.dricu@live.co.uk 
alone or in combination with conventional treatment for several types of malignancies. The substances gained attention as chemotherapeutic agents because of their cytotoxic effect on malignant cells as well as their favorable toxicity profile in vivo. (5) Dyes have been demonstrated to have antiproliferative effects on cancer cells by inhibiting RTK's (receptor tyrosine kinases) signaling and inducing apoptosis in cancer cells. $(5,6)$ Some of them are also able to inhibit intracellular signal transduction pathways in vivo. $(5,6)$ These compounds are reported to be involved in mutagenesis and carcinogenesis. These properties of dyes open a therapeutic window for the treatment of malignant diseases, including glioblastomas.

The current review describes the recent findings regarding the biological activity of some natural (curcumin, quercetin) and synthetic (helianthin, methyl red and methyl yellow) dyes. The review presents the efficacy of these drugs and their mechanisms of action in several types of cancers focusing on glioblastomas.

\section{NATURAL DYE COMPOUNDS}

\section{Curcumin}

Curcumin (diferuloymethane) is a polyphenol derived from the rhizome of the herb Curcuma lon$g a$, popularly known as turmeric. The substance is hydrophobic therefore is poorly soluble in water or other neutral solvents, therefore it's bioavailability is poor. The substance is rapidly metabolized in intestine and also in the liver, so in the end approximately $60-70 \%$ of an oral dose gets eliminated in the feces. (7) In clinical studies, curcumin was administrated orally in high doses but the plasmatic levels were also very low. In the last 2 decades the bioavailability of cucumin was enhanced by using new delivery systems like: micelles, (8) liposomal vesicles (9), nanoparticles $(9,10)$, nanoemulsions (11), and phospholipid complexes. (12) The rhizome of Curcuma longa contains a complex of curcuminoids which is formed by: diferuloymethane, demetoxycurcumin, bisdemetoxycurcumin and cyclocurcumin. Commercial curcumin contains only the first three curcuminoids. (13) Turmeric has been used since ancient times (over 2000 years ago) in Asia as a spice, for fabric dyes, cosmetics but also in Indian Ayurvedic medicine for treatment of some disorders like: infections, burns, allergies, rheumatisms, liver disorders, and so on. (14) Nowadays, curcumin is used in in vivo and in vitro studies, for treatment of several diseases such as anti- septic, antioxidant, anti-inflammatory, but also anti-proliferative, anti-metastatic anti-angiogenic and antimutagenic. $(15,16)$ The substance was used for cancer treatment $(17,18)$ but also for prevention of various types of cancer. $(19,20)$ After the positive results of the first clinical trial in 1987, when turmeric was used for skin cancer treatment, (21) curcumin (either alone or in combination with other chemotherapic agents) was used in numerous clinical trials for the prevention or treatment of various cancers like: colorectal cancer (19), pancreatic cancer (22), breast cancer (17), prostate cancer (23), multiple myeloma (24), lung cancer (25), oral cancer (26), head and neck cancer. (27) In the last decades, several research groups investigated the efficacy of curcumin treatment in GB cell lines. The first report which confirmed the antiproliferative effect of turmeric in GB cell lines dates from 2003. After that, researchers observed that curcumin treatment induced the activation of proapoptotic signals and inhibited anti-apoptotic genes. (29) (Fig. 1) The substance is also capable to inhibit NF-kB signaling pathways, to decrease the expression of genes like Bcl family or IAP ( which normally confer resistance to chemotherapy), to inhibit the expression of MGMT, Ku70, Ku 80 and DNA-PKcs (DNA repair enzymes), which are believed to be involved in GB cell resistance to chemotherapy and radiotherapy. In a study by K.M. Dhandapani et al, turmeric was shown to up-regulate the p53 expression in GB cells. (30) After the inhibition of some anti-apoptotic pathways, like $\mathrm{Bcl} 2, \mathrm{NF}-\mathrm{Kb}$ or IAPs, it was found that curcumin can activate PARP and caspase 3 cascades and in consequences to initiate GB cells apoptosis. $(29,31)$ Curcumin is also able to inhibit ING4 signaling pathway in GB cell lines (32) and also activates a non-apoptotic autophagy signal in GB cells, as a result of $\mathrm{Akt} / \mathrm{mTOR} / \mathrm{p} 7056 \mathrm{~K}$ pathway inhibition and ERK pathway activation. (33) (Fig.1) Curcumin induces differentiation cascade in GB - initiating cells, both in vitro and in vivo, followed by decreased self-renewal and clonogenic ability. (34) Furthermore, curcumin treatment inhibits the expression of MMPs (-1,-3, and -14) molecules through the suppression of PKC and MAPK signaling pathways (35) and by the inhibition of AP-1. (36) It is also capable to inhibit G6PT gene expression (37) and to activated proteolytic pathways through both mitochondria or death-receptor (38) or to induce apoptosis mediated through TRAIL/ Apo2L. (39) It was also observed that the substance can sensitize GB cells to other chemotherapeutic agents or to radiotherapy. (30) There are only a few 
in vivo studies that used curcumin as a treatment in GB tumors. The first in vivo study which results were presented in 2007 used subcutaneous xenograft model of GB. The administration of curcumin inhibited tumor growth and induced autophagy. (40) The next study published in 2010 demonstrated that the administration of turmeric to immune compromised mice diminished the growth of the tumor and improved survival. The compound was able to easy penetrate the blood brain barrier, altering the activities of matrix metalloproteinase -9 , down-regulating CD31 and CD105 mRNA, and reducing the hemoglobin content in GB cells. (41) In a study by Zanotto-Filho, A, published in 2012, curcumin was used to treat GB immune-competent rats. The drug was administrated intraperitoneal and determined a decrease of $80 \%$ of the tumor volume. The substance proved no toxicity and the normal tissues were minimally affected by the treat- ment. The authors observed that the treatment affected some intracellular pathways like: PI3-Akt, $\mathrm{NFkB}$, inhibited Bcl-2 expression and altered the mitochondrial activity independently of p53 and PTEN. (42) The preliminary results of a clinical trial which used curcumin in association with other treatments for a personalized and targeted therapy in pediatric brain tumors were also published in 2012. (43) The results are promising showing that individualized targeted therapy might be superior to traditional therapy.

\section{Quercetin}

Another natural dye compound used in GB therapy is quercetin $\left(3,3^{\prime}, 4^{\prime}, 5,7\right.$-pentahydroxyflavone). The substance is a flavonol extracted and isolated from Sophora Japonica L. The substance is found in vegetables, fruits, tea, olive oil, and so on. Due to its chemical structure quercetin easily forms co-

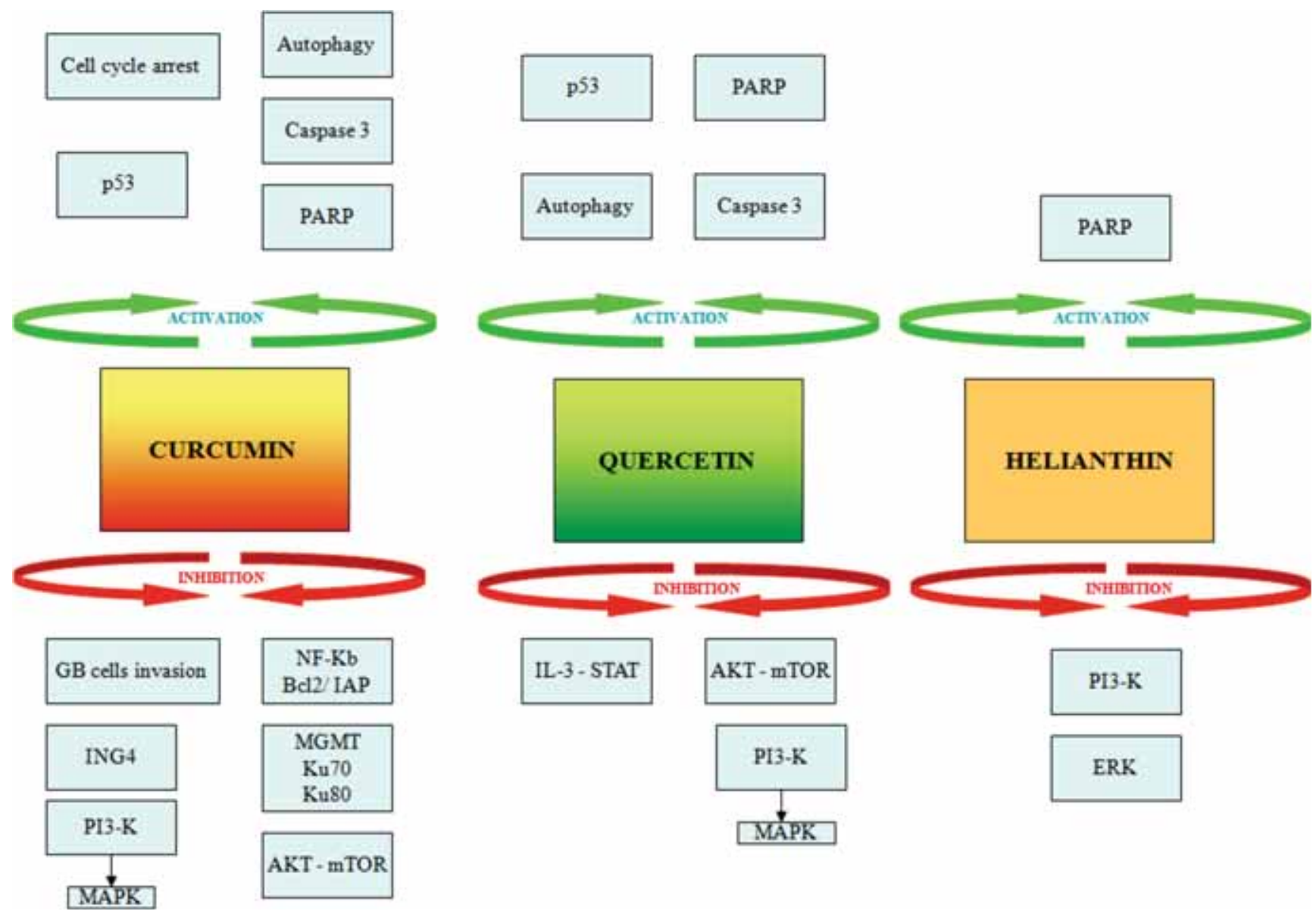

FIGURE 1. Molecular targets of curcumin, quercetin and helianthin in glioblastomas

Abbreviations

GB - Glioblastoma; PARP - Poly (ADP-ribose) polymerase; P53 - Protein mass of 53 kDa; ING4 - Inhibitor of growth protein 4;

PI3-K - Phosphoinositide 3-kinase; MAPK - Mitogen-activated protein kinase; NF-Kb - Nuclear factor kappa-light-chain-enhancer of activated B cells; Bcl-2 - B-cell lymphoma 2; IAP - Inhibitors of apoptosis proteins; MGMT - O6-methylguanine-DNA methyltransferase; Ku70 - 70-kDa protein; Ku80 - 80-kDa protein; AKT (PKB) - protein kinase B; mTOR - Mammalian target of rapamycin; IL-3 - Protein kinase B; STAT - Signal Transducer and Activator of Transcription 
loured complexes with metal ions. The drug is poorly soluble in water. The bioavailability is also reduced due to its poor absorption and rapid metabolism. In 2000, it was reported that quercetin glucosides are completely hydrolyzed in ileostomy patients before absorption. (45) In the last years, researchers focused on developing new drug delivery approaches for quercetin, like: prodrugs $(46,47)$, inclusion complexes (48), nanocrystals, microemulsions (49), liposomes, phospholid formulations (50), quercetin-encapsulated polymer nanoparticles (48), quercetin polymeric micelles (51) etc.

Quercetin has many molecular mechanisms of action. It is capable to influence the activity of several enzyme systems both in vitro and in vivo. Among these enzymes are protein kinases. In fact, quercetin was probably the first described tyrosine kinase inhibitor. (52) and it was the first tyrosine kinase inhibitor tested in phase I clinical trial.(53) The substance is also capable to down regulate the mutant p53 protein, facilitating cell death. (54) and can arrest cancer cells (leukemia, gastric) in the late G1 phase of the cell cycle. (55)The drug has estrogen receptor binding capacity (56), can inhibit heat shock proteins (57) and the expression of Ras (58) and phosphatidyl-3 kinase proteins. (59) and Iphosphatidylinosotol-4 kinase (60) involved in signaling pathways. Quercetin treatment inhibited malignant cell growth in cancers like: breast, ovarian $(61,62)$, gastric $(63)$, colon, bladder, head and neck, lung (65), leukemia (66), melanoma. (67) (The animal studies that used quercetin demonstrated that the substance seems to be a selective inhibitor of the growth of malignant cells. $(68,69)$ The FDA (Federal Drug Administration) has approved the administration of quercetin in humans in 1975. The dose of 100mg quercetin was well tolerated and did not induced side effects. (70) The results of the first clinical trial that used quercetin as treatment for patients diagnosed with cancer no longer responsive to standard therapies were published in 1996. (53)

In the last decades, several research groups investigated the efficacy of quercetin treatment in various GB cell lines. The first report, which confirmed the antiproliferative effect of , 3', 4', 5,7-pentahydroxyflavone in GB cell lines, dates from 1996 (71) and it was followed by a number of studies that demonstrated that quercetin exerts its by its antiproliferative effect on GB cells by different mechanisms: inhibition of PI3K-AKT/PKB pathway and activation of ERK-dependent COX-2/PGE (2) (73) and abrogation of IL-3/STAT3 signaling. (74) It was also proved that quercetin promotes apoptosis mediated by caspase-3and influences the feedback balance of MDM - P53 in GB cells. (75) (Fig.1)

The drug is capable to inhibit Hsp and to sensitize GB cells to termozolomide treatment. $(76,77)$ Used in combination with sorafenib, quercetin induces programmed cell death in GB cells. The same effect of the substance was found when used in combination with imperatorin. (77) Until now, there are no clinical studies using quercetin as a treatment on GB patients.

\section{Synthetic azo-dyes}

Until now only helianthin, methyl red and methyl yellow effects were studied in GB therapy in vitro. In our previously studies, we found that among these 3 substances only helianthin had the capability to induce cytotoxicity in GB cell lines. Helianthin induces a reduction of EGFR, IGF-1R, PI3-K and ERK1/2 phosphorylation in GB cells. The drug also induced cleavage of PARP, without affecting the expression of $\mathrm{Bcl} 2$ in the studied GB cell lines. Until now there are no in vivo studies that used helianthin as an antitumor agent. (78) (Fig.1)

\section{CONCLUSIONS}

Clinical results from conventional therapy have been limited. New class of drugs, potentially useful for the treatment of GB patients is required. Dye compounds could be a very promising drugs in cancer treatments. Although much more work is required to test their effect in vivo and in vitro, it is hoped that these compound will help improve the efficacy of anticancer regimes in glioblastoma

Acknowledgement: This paper was published under the frame of European Social Found, Human Resources Development Operational Programme 2007-2013, Project no. POSDRU/159/1.5/S/136893 and PN-II-ID-PCE-2011-3-1041 UEFISCDI, Romania 


\section{REFERENCES}

1. Louis D.N., Ohgaki H., Wiestler O.D., et al. The 2007 WHO classification of tumours of the central nervous system. Acta Neuropathol. 2007; 114:97-109.

2. Ostrom Q.T., Gittleman H., Farah P., et al. CBTRUS statistical report: Primary brain and central nervous system tumors diagnosed in the United States in 2006-2010. Neuro Oncol. 2013; 15 (Supplement) 2:-56.

3. Stupp R., Tonn J.C., Brada M., Pentheroudakis G. High-grade malignant glioma: ESMO Clinical Practice Guidelines for diagnosis, treatment and follow-up. Ann Oncol. 2010; 21 (Supplement) 5:190-3.

4. Maheshwari R.K., Singh A.K., Gaddipati J., Srimal R.C. Multiple biological activities of curcumin: a short review. Life Sci. 2006; 78:2081-7.

5. Duvoix A., Blasius R., Delhalle S., et al. Chemopreventive and therapeutic effects of curcumin. Cancer Lett. 2005; 223:181-90.

6. Arbiser J.L., Klauber N., Rohan R., et al. Curcumin is an in vivo inhibitor of angiogenesis. Mol Med. 1998; 4:376-83.

7. Pan M.H., Huang T.M., Lin J.K. Biotransformation of curcumin through reduction and glucuronidation in mice. Drug Metab Dispos. 1999; 27:486-94.

8. Ma Z., Haddadi A., Molavi O., Lavasanifar A., Lai R., Samuel J. Micelles of poly(ethylene oxide)-b-poly(epsilon-caprolactone) as vehicles for the solubilization, stabilization, and controlled delivery of curcumin. J Biomed Mater Res A. 2008; 86:300-10.

9. Thangapazham R.L., Puri A., Tele S., Blumenthal R., Maheshwari R.K. Evaluation of a nanotechnology-based carrier for delivery of curcumin in prostate cancer cells. Int J Oncol. 2008; 32:1119-23.

10. Bisht S., Feldmann G., Soni S., Ravi R., Karikar C., Maitra A. Polymeric nanoparticle-encapsulated curcumin ("nanocurcumin"): a novel strategy for human cancer therapy. J Nanobiotechnology. 2007; 5:3.

11. Ganta S., Amiji M. Coadministration of Paclitaxel and curcumin in nanoemulsion formulations to overcome multidrug resistance in tumor cells. Mol Pharm. 2009; 6:928-39.

12. Maiti K., Mukherjee K., Gantait A., Saha B.P., Mukherjee P.K. Curcumin-phospholipid complex: Preparation, therapeutic evaluation and pharmacokinetic study in rats. Int J Pharm. 2007; 330:155-63.

13. Anand P., Sundaram C., Jhurani S., Kunnumakkara A.B., Aggarwal B.B. Curcumin and cancer: an "old-age" disease with an "age-old" solution. Cancer Lett. 2008; 267:133-64.

14. Aggarwal B.B., Sundaram C., Malani N., Ichikawa H. Curcumin: the Indian solid gold. Adv Exp Med Biol. 2007; 595:1-75.

15. Hatcher H., Planalp R., Cho J., Torti F.M., Torti S.V. Curcumin: from ancient medicine to current clinical trials. Cell Mol Life Sci. 2008; 65:1631-52

16. Moon H.J., Ko W.K., Han S.W., et al. Antioxidants, like coenzyme Q10, selenite, and curcumin, inhibited osteoclast differentiation by suppressing reactive oxygen species generation. Biochem Biophys Res Commun. 2012; 418:247-53.

17. Bayet-Robert M., Kwiatkowski F., Leheurteur M., et al. Phase I dose escalation trial of docetaxel plus curcumin in patients with advanced and metastatic breast cancer. Cancer Biol Ther. 2010; 9:8-14.

18. Golombick T., Diamond T.H., Manoharan A., Ramakrishna R. Monoclonal gammopathy of undetermined significance, smoldering multiple myeloma, and curcumin: a randomized, double-blind placebo-controlled cross-over $4 \mathrm{~g}$ study and an open-label $8 \mathrm{~g}$ extension study. Am J Hematol. 2012; 87:455-60.

19. Carroll R.E., Benya R.V., Turgeon D.K., et al. Phase lla clinical trial of curcumin for the prevention of colorectal neoplasia. Cancer Prev Res (Phila). 2011; 4:354-64.
20. Cheng A.L., Hsu C.H., Lin J.K., et al. Phase I clinical trial of curcumin, a chemopreventive agent, in patients with high-risk or pre-malignant lesions. Anticancer Res. 2001; 21:2895-900.

21. Kuttan R., Sudheeran P.C., Josph C.D. Turmeric and curcumin as topical agents in cancer therapy. Tumori. 1987; 73:29-31.

22. Epelbaum R., Schaffer M., Vizel B., Badmaev V., Bar-Sela G. Curcumin and gemcitabine in patients with advanced pancreatic cancer. Nutr Cancer. 2010; 62:1137-41.

23. Ide H., Tokiwa S., Sakamaki K., et al. Combined inhibitory effects of soy isoflavones and curcumin on the production of prostate-specific antigen. Prostate. 2010; 70:1127-33.

24. Marin Y.E., Wall B.A., Wang S., et al. Curcumin downregulates the constitutive activity of NF-kappaB and induces apoptosis in novel mouse melanoma cells. Melanoma Res. 2007; 17:274-83.

25. Hastak K., Lubri N., Jakhi S.D., et al. Effect of turmeric oil and turmeric oleoresin on cytogenetic damage in patients suffering from oral submucous fibrosis. Cancer Lett. 1997; 116:265-9.

26. Chainani-Wu N., Silverman S., Jr., Reingold A., et al. A randomized, placebo-controlled, double-blind clinical trial of curcuminoids in oral lichen planus. Phytomedicine. 2007; 14:437-46.

27. Kim S.G., Veena M.S., Basak S.K., et al. Curcumin treatment suppresses IKKbeta kinase activity of salivary cells of patients with head and neck cancer: a pilot study. Clin Cancer Res. 2011; 17:5953-61.

28. Ambegaokar S.S., Wu L., Alamshahi K., et al. Curcumin inhibits dose-dependently and time-dependently neuroglial cell proliferation and growth. Neuro Endocrinol Lett. 2003; 24:469-73.

29. Karmakar S., Banik N.L., Ray S.K. Curcumin suppressed anti-apoptotic signals and activated cysteine proteases for apoptosis in human malignant glioblastoma U87MG cells. Neurochem Res. 2007; 32:2103-13.

30. Dhandapani K.M., Mahesh V.B., Brann D.W. Curcumin suppresses growth and chemoresistance of human glioblastoma cells via AP-1 and NFkappaB transcription factors. J Neurochem. 2007; 102:522-38.

31. Kang S.K., Cha S.H., Jeon H.G. Curcumin-induced histone hypoacetylation enhances caspase-3-dependent glioma cell death and neurogenesis of neural progenitor cells. Stem Cells Dev. 2007; 15:165-74

32. Liu E., Wu J., Cao W., et al. Curcumin induces G2/M cell cycle arrest in a p53-dependent manner and upregulates ING4 expression in human glioma. J Neurooncol. 2007; 85:263-70.

33. Shinojima N., Yokoyama T., Kondo Y., Kondo S. Roles of the Akt/ $\mathrm{mTOR} / \mathrm{p} 70 \mathrm{~S} 6 \mathrm{~K}$ and ERK1/2 signaling pathways in curcumin-induced autophagy. Autophagy. 2007; 3:635-7.

34. Zhuang W., Long L., Zheng B., et al. Curcumin promotes differentiation of glioma-initiating cells by inducing autophagy. Cancer Sci. 2012; 103:684-90.

35. Woo M.S., Jung S.H., Kim S.Y., et al. Curcumin suppresses phorbol ester-induced matrix metalloproteinase-9 expression by inhibiting the PKC to MAPK signaling pathways in human astroglioma cells. Biochem Biophys Res Commun. 2005; 335:1017-25.

36. Kim S.Y., Jung S.H., Kim H.S. Curcumin is a potent broad spectrum inhibitor of matrix metalloproteinase gene expression in human astroglioma cells. Biochem Biophys Res Commun. 2005; 337:510-6.

37. Belkaid A., Copland I.B., Massillon D., Annabi B. Silencing of the human microsomal glucose-6-phosphate translocase induces glioma cell death: potential new anticancer target for curcumin. FEBS Lett. 2006; 580:3746-52. 
38. Karmakar S., Banik N.L., Patel S.J., Ray S.K. Curcumin activated both receptor-mediated and mitochondria-mediated proteolytic pathways for apoptosis in human glioblastoma T98G cells. Neurosci Lett. 2006; 407:53-8.

39. Gao X., Deeb D., Jiang H., Liu Y.B., Dulchavsky S.A., Gautam S.C. Curcumin differentially sensitizes malignant glioma cells to TRAIL/Apo2L-mediated apoptosis through activation of procaspases and release of cytochrome c from mitochondria. J Exp Ther Oncol. 2005; 5:39-48.

40. Aoki H., Takada Y., Kondo S., Sawaya R., Aggarwal B.B., Kondo Y. Evidence that curcumin suppresses the growth of malignant gliomas in vitro and in vivo through induction of autophagy: role of Akt and extracellular signal-regulated kinase signaling pathways. Mol Pharmacol. 2007; 72:29-39.

41. Perry M.C., Demeule M., Regina A., Moumdjian R., Beliveau R. Curcumin inhibits tumor growth and angiogenesis in glioblastoma xenografts. Mol Nutr Food Res. 2010; 54:1192-201.

42. Zanotto-Filho A., Braganhol E., Edelweiss M.I., et al. The curry spice curcumin selectively inhibits cancer cells growth in vitro and in preclinical model of glioblastoma. J Nutr Biochem. 2012; 23:591-601.

43. Wolff J.E., Brown R.E., Buryanek J., Pfister S., Vats T.S., Rytting M.E. Preliminary experience with personalized and targeted therapy for pediatric brain tumors. Pediatr Blood Cancer.; 59:27-33.

44. Cornard J.P., Dangleterre L., Lapouge C. Computational and spectroscopic characterization of the molecular and electronic structure of the $\mathrm{Pb}$ (II)-quercetin complex. J Phys Chem A. 2005; 109:10044-51.

45. Walle T., Otake Y., Walle U.K., Wilson F.A. Quercetin glucosides are completely hydrolyzed in ileostomy patients before absorption. J Nutr. 2000; 130:2658-61.

46. Puoci F., Morelli C., Cirillo G., et al. Anticancer activity of a quercetin-based polymer towards HeLa cancer cells. Anticancer Res. 2012; 32:2843-7.

47. Lin C.F., Leu Y.L., Al-Suwayeh S.A., Ku M.C., Hwang T.L., Fang J.Y. Anti-inflammatory activity and percutaneous absorption of quercetin and its polymethoxylated compound and glycosides: the relationships to chemical structures. Eur J Pharm Sci. 2012; 47:857-64.

48. Kakran M., Shegokar R., Sahoo N.G., Shaal L.A., Li L., Muller R.H. Fabrication of quercetin nanocrystals: comparison of different methods. Eur J Pharm Biopharm.2012;80:113-21.

49. Gao Y., Wang Y., Ma Y., et al. Formulation optimization and in situ absorption in rat intestinal tract of quercetin-loaded microemulsion. Colloids Surf B Biointerfaces. 2009; 71:306-14.

50. Dhawan S., Kapil R., Singh B. Formulation development and systematic optimization of solid lipid nanoparticles of quercetin for improved brain delivery. J Pharm Pharmacol. 201; 63:342-51.

51. Tan B.J., Liu Y., Chang K.L., Lim B.K., Chiu G.N. Perorally active nanomicellar formulation of quercetin in the treatment of lung cancer. Int J Nanomedicine. 2012; 7:651-61.

52. Glossmann H., Presek P., Eigenbrodt E. Quercetin inhibits tyrosine phosphorylation by the cyclic nucleotide-independent, transforming protein kinase, pp60src. Naunyn Schmiedebergs Arch Pharmacol. 1981; 317:100-2.

53. Ferry D.R., Smith A., Malkhandi J., et al. Phase I clinical trial of the flavonoid quercetin: pharmacokinetics and evidence for in vivo tyrosine kinase inhibition. Clin Cancer Res. 1996; 2:659-68.

54. Avila M.A., Cansado J., Harter K.W., Velasco J.A., Notario V. Quercetin as a modulator of the cellular neoplastic phenotype. Effects on the expression of mutated $\mathrm{H}$-ras and $\mathrm{p} 53$ in rodent and human cells. Adv Exp Med Biol. 1996; 401:101-10.

55. Yoshida M., Yamamoto M., Nikaido T. Quercetin arrests human leukemic T-cells in late G1 phase of the cell cycle. Cancer Res. 1992; 52:6676-81.
56. Piantelli M., Maggiano N., Ricci R., et al. Tamoxifen and quercetin interact with type II estrogen binding sites and inhibit the growth of human melanoma cells. J Invest Dermatol. 1995; 105:248-53.

57. Hansen R.K., Oesterreich S., Lemieux P., Sarge K.D., Fuqua S.A. Quercetin inhibits heat shock protein induction but not heat shock factor DNA-binding in human breast carcinoma cells. Biochem Biophys Res Commun. 1997; 239:851-6.

58. Ranelletti F.O., Maggiano N., Serra F.G., et al. Quercetin inhibits p21-RAS expression in human colon cancer cell lines and in primary colorectal tumors. Int J Cancer. 2000; 85:438-45.

59. Matter W.F., Brown R.F., Vlahos C.J. The inhibition of phosphatidylinositol 3-kinase by quercetin and analogs. Biochem Biophys Res Commun. 1992; 186:624-31.

60. Yeh Y.A., Olah E., Wendel J.J., Sledge G.W., Jr., Weber G. Synergistic action of taxol with tiazofurin and methotrexate in human breast cancer cells: schedule-dependence. Life Sci. 1994; 54:431-5.

61. Deng X.H., Song H.Y., Zhou Y.F., Yuan G.Y., Zheng F.J. Effects of quercetin on the proliferation of breast cancer cells and expression of survivin. Exp Ther Med. 2013;6:1155-8.

62. Gao X., Wang B., Wei X., et al. Anticancer effect and mechanism of polymer micelle-encapsulated quercetin on ovarian cancer. Nanoscale. 2012; 4:7021-30.

63. Borska S., Chmielewska M., Wysocka T., Drag-Zalesinska M., Zabel M., Dziegiel P. In vitro effect of quercetin on human gastric carcinoma: targeting cancer cells death and MDR. Food Chem Toxicol. 2012; 50:3375-83.

64. Zhang H., Zhang M., Yu L., Zhao Y., He N., Yang X. Antitumor activities of quercetin and quercetin-5, 8 -disulfonate in human colon and breast cancer cell lines. Food Chem Toxicol. 2012; 50:1589-99.

65. Caltagirone S., Ranelletti F.O., Rinelli A., et al. Interaction with type Il estrogen binding sites and antiproliferative activity of tamoxifen and quercetin in human non-small-cell lung cancer. Am J Respir Cell Mol Biol. 1997; 17:51-9.

66. Maso V., Calgarotto A.K., Franchi G.C., Jr., et al. Multitarget effects of quercetin in leukemia. Cancer Prev Res (Phila). 2014; 7:1240-50.

67. Cao H.H., Tse A.K., Kwan H.Y., et al. Quercetin exerts anti-melanoma activities and inhibits STAT3 signaling. Biochem Pharmacol. 2013; 87:424-34.

68. Castillo M.H., Perkins E., Campbell J.H., et al. The effects of the bioflavonoid quercetin on squamous cell carcinoma of head and neck origin. Am J Surg. 1989; 158:351-5.

69. Yuan Z.P., Chen L.J., Fan L.Y., et al. Liposomal quercetin efficiently suppresses growth of solid tumors in murine models. Clin Cancer Res. 2006; 12:3193-9.

70. Gugler R., Leschik M., Dengler H.J. Disposition of quercetin in man after single oral and intravenous doses. Eur J Clin Pharmacol. 1975; 9:229-34.

71. Calias P., Galanopoulos T., Maxwell M., et al. Synthesis of inositol 2-phosphate-quercetin conjugates. Carbohydr Res. 1996; 292:83-90.

72. Pozsgai E., Bellyei S., Cseh A., et al. Quercetin increases the efficacy of glioblastoma treatment compared to standard chemoradiotherapy by the suppression of PI-3-kinase-Akt pathway. Nutr Cancer. 2013; 65:1059-66.

73. Chiu W.T., Shen S.C., Chow J.M., Lin C.W., Shia L.T., Chen Y.C. Contribution of reactive oxygen species to migration/invasion of human glioblastoma cells U87 via ERK-dependent COX-2/PGE(2) activation. Neurobiol Dis. 2010; 37:118-29.

74. Kim H., Moon J.Y., Ahn K.S., Cho S.K. Quercetin induces mitochondrial mediated apoptosis and protective autophagy in human glioblastoma U373MG cells. Oxid Med Cell Longev. 2013; :59649-6.

75. Wang H., Yuan Z., Chen Z., Yao F., Hu Z., Wu B. Effect of quercetin on glioma cell U87 apoptosis and feedback regulation of MDM2-p53. Nan Fang Yi Ke Da Xue Xue Bao. 2014; 34:686-9. 
76. Sang D.P., Li R.J., Lan Q. Quercetin sensitizes human glioblastoma cells to temozolomide in vitro via inhibition of Hsp27. Acta Pharmacol Sin. 2014; 35:832-8.

77. Jakubowicz-Gil J., Langner E., Badziul D., Wertel I., Rzeski W. Silencing of Hsp27 and Hsp72 in glioma cells as a tool for pro- grammed cell death induction upon temozolomide and quercetin treatment. Toxicol Appl Pharmacol.2014; 273:580-9.

78. Alexandru O., Dragutescu L., Tataranu L., et al. Helianthin induces antiproliferative effect on human glioblastoma cells in vitro. J Neurooncol. 2011; 100:9-18. 